\title{
Structural Integrity Assessment of Welded Pipeline Designed with Reduced Safety
}

\author{
Lazar JEREMIĆ, Aleksandar SEDMAK*, Blagoj PETROVSKI, Branislav ĐORĐEVIĆ, Simon SEDMAK
}

\begin{abstract}
The main goal of this paper was to assess the integrity of welded joints in the main pipeline of the reversible hydropower plant "Bajina Bašta". Japanese steel Sumiten 80P (SM 80P) was used as the parent material. European recommendation for pipeline safety factor is equal to 1.7 and this value was used for calculations of the RHPP "Bajina Bašta", whereas the value recommended by Japanese standards is 2.1. A relatively small safety factor, which is different from the Japanese recommendation (since the material itself is Japanese), represented one of the main reasons for a detailed investigation of the pipeline structural integrity and safety, using the prototype. In the case of pressure vessels, the welded joint is a location of stress concentration, which can act in the same way as residual stresses. Assessment of prototype test results is possible to perform based on stress and strain calculations of vessels with ideal geometry. For this reason, the solution for thin-walled vessels is given, both in elastic and elastic-plastic areas. Numerous tests were performed in order to obtain a reliability assessment necessary for the construction of the pipeline, since the consequences of potential failure would be disastrous in this case. A numerical simulation, based on the experimentally determined mechanical properties of the material used, was also performed in order to obtain the stress/strain distribution. These results were then compared to the experimentally obtained ones, and it was concluded that there is a good level of compliance between numerical and experimental results.
\end{abstract}

Keywords: finite element method; structural integrity; Sumiten 80P; undermatched welded joint

\section{INTRODUCTION}

Penstocks in hydro-electrical power plants are generally exposed to high stresses. In the case of the hydro-electrical power plant "Bajina Bašta", two different designs and steels were considered:

1. The selection of common mild steel of yield strength $350 \mathrm{MPa}$ required expensive design with 2 penstocks and 2 tunnels.

2. For only one penstock the application of high strength low alloyed (HLSA) steel of yield strength level $700 \mathrm{MPa}$ was inevitable, bringing about additional problems due to cracking sensitivity in respect to welding of such a steel.

Since the latter solution was adopted, additional "fitness for purpose" was required, in order to understand better crack significance. The following fact additionally contributed to make a decision to produce two full scale prototypes of this penstock in order to gather the data about its integrity:

1. The plate thickness of the selected steel (Sumiten 80P, made by "Sumitomo", Japan) was maximum $47 \mathrm{~mm}$, leading to safety margin of only 1.7 , significantly lower than the recommended value $2.07,[1]$.

Two identical full-scale pressure vessels, modelled as prototype of the penstock most stressed part (Fig. 1), were produced by welding of SUMITEN 80P, $47 \mathrm{~mm}$ thick plates. The burst test was performed on pre-cracked model for testing resistance to fast fracture and crack arrest properties, whereas the hydro-pressure test on a model with no crack enabled the post-yield experimental analysis of weldments, being the focus of this paper.

Most pressure vessels are welded using the automatic submerged arc welding (SAW), due to its high productivity. Anyhow, manual arc welding (MAW) is still important and often used, at least for repair, so it will be considered here as well. In any case, due to HSLA steel sensitivity to cracking, so-called undermatching effect is a preferable option for welded joints since the overmatching would cause additional welding problems. The undermatching effect, as well as all other constraint effects, requires essentially different approach to welded structure analysis, [1-11], since plastic strain in such weld metal is inevitable, $[12,13]$.

In this paper, the experimental data obtained on the prototype was used for detailed analysis of welded joints, as well as to verify numerical simulation of prototype behaviour.

\section{PROTOTYPE CONSTRUCTION}

The prototype was constructed by taking into account the geometry, measures and wall thickness at the most critically loaded part of the pipeline (diameter of $4.2 \mathrm{~m}$, with a $5^{\circ}$ bend, wall thickness of $47 \mathrm{~mm}$ ). In order to reduce the effect of lids, reinforcement ribs were placed at both ends of the mantle. The plates were cold bent, and the edges were prepared using gas cutting and grinding. Manufacturing of the prototype involved all combinations of welded joint positions and welding procedures used for the pipeline.

The geometry of the prototype which simulates the most critically loaded part of the pipeline consists of a cylindrical mantle with a diameter of $4200 \mathrm{~mm}$ and a $5^{\circ}$ bend in the pipeline transition area, was closed off using two lids, and is shown in Fig. 1. Welding processes included manual arc (MAW) and submerged arc welding (SAW).

The prototype was made of six sheets, with a thickness of $47 \mathrm{~mm}$, Sumiten 80P steel, joined by SAW and MAW. The prototype consisted of three rings, made from four longitudinal SAW joints (LS1, LS2, LS3, LS4) and two longitudinal MAW joints (LM1, LM2), joined by circumferential manually welded joints (CM), and automatically welded joint (CS). Tests were performed on LS2, LM2, $\mathrm{CM}$ and $\mathrm{CS}$ joints. Chemical composition and mechanical properties of sheets and filler materials used for both automatic and manual welding procedures are given elsewhere, [1].

Fig. 2 shows strain gauge distribution on prototype mantle, used to monitor welded joints during pressurizing. 

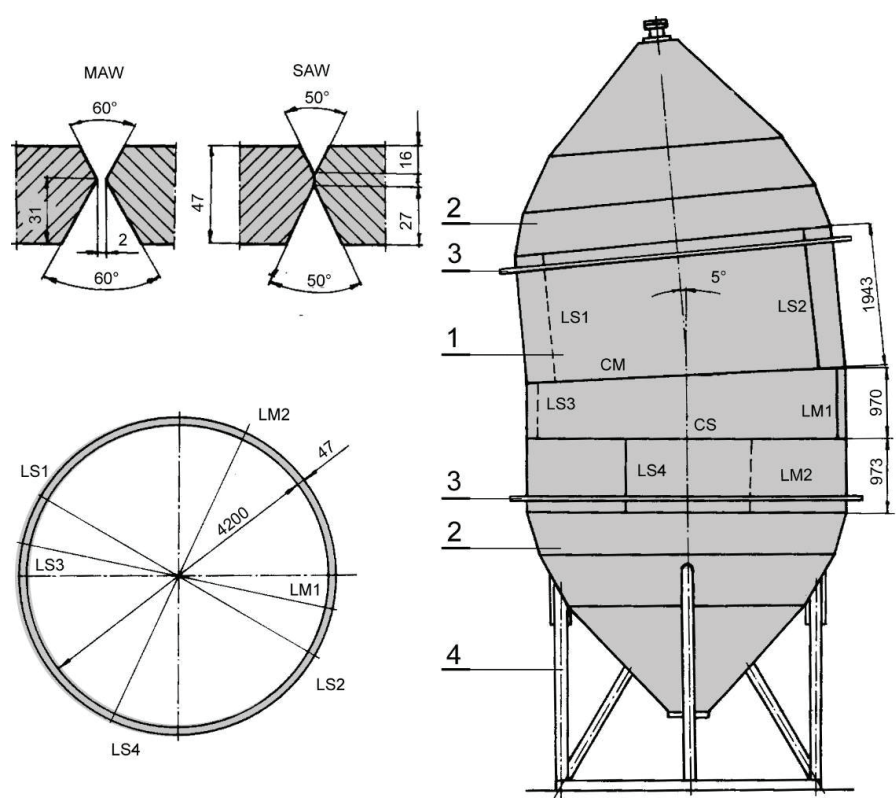

Figure 1 The design and dimensions of the pipeline prototype used in the stress-strain state analysis

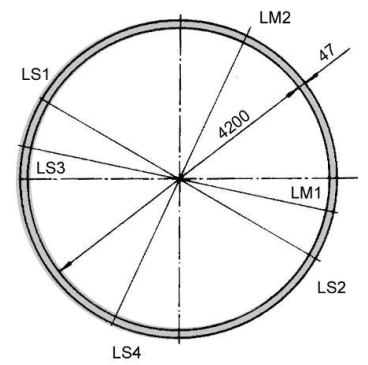

$1^{\circ}-6^{\circ} \quad$ Large-strain Strain Gauges $5 \mathrm{~mm}$

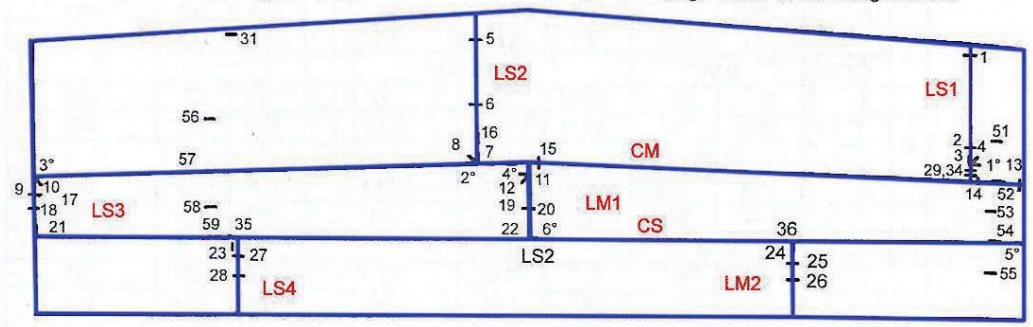

Figure 2 Strain gauge distribution on the prototype

\section{PROTOTYPE TESTING}

Hydrostatic tests of prototypes, by adding adequate water pressure was performed under maximum working stress conditions, as well as under conditions where these stresses were exceeded by $30 \%$. After the hydrostatic test, corresponding specimens were cut out of the prototype and various tests were performed in order to compare these results to the unloaded specimens, thus assessing the effects of overload and initial plastic strain. This involved static tests and quick fracture tests.

Prototype strains were measured by 51 strain gauges and 10 Moire grids. Hydrostatic testing was performed in three stages, always followed by unloading:

1) Checking of the measuring system by increased internal pressure in the prototype from 0 to $2.95 \mathrm{MPa}$.

2) Loading the prototype up to work stress level, by increasing the internal pressure from 0 to $9 \mathrm{MPa}$, with hold on under pressure 73.5 bar for two hours.

3) Overloading the prototype by $33.3 \%$, by increasing the pressure from 0 to $12.05 \mathrm{MPa}$, corresponding to $77.5 \%$ of SAW joint yield stress $(687 \mathrm{MPa})$. Since the acoustic emission indicated noticeable activity, loading was stopped.

Strain gauges had nominal lengths of $5 \mathrm{~mm}$, denoted by $1-36$, and $50 \mathrm{~mm}$, denoted by $51-59$, Fig. 2, [1]. Strain gauge 3 was connected to a pressure sensor, for the purpose of monitoring the continuous change of strain with pressure. Strain gauges 30-33 were connected to the measuring system only during the third test stage (internal pressure increase from 0 to $12.05 \mathrm{MPa}$ ), thus the results obtained from them are incomplete.

Focus will be here on the vertical weld LS4, Fig. 1. Welded joint LS4 represents one of the most critical locations in the prototype, due to its vicinity to the $5^{\circ}$ bend.

Fig. 3 shows the comparison of tangential strain from strain gauges 23 and 27 with the equivalent strain. Analytical expressions relating to strains and stresses in elasticity are as follows:

$\varepsilon_{t}=\frac{1}{E}\left(\sigma_{t}-v \sigma_{z}\right) ; \varepsilon_{z}=\frac{1}{E}\left(\sigma_{z}-v \sigma_{t}\right) ; \varepsilon_{r}=-\frac{1}{E}\left(\sigma_{t}+\sigma_{z}\right)$

$\varepsilon_{i}=\frac{\sqrt{2}}{2(1+v)} \sqrt{\left(\varepsilon_{t}-\varepsilon_{z}\right)^{2}+\left(\varepsilon_{z}-\varepsilon_{r}\right)^{2}+\left(\varepsilon_{r}-\varepsilon_{t}\right)^{2}}$

$\varepsilon_{i}=18.44 \times 10^{-5} p$

where $\varepsilon_{t}$ is tangential, $\varepsilon_{z}$ axial and $\varepsilon_{i}$ equivalent strain.

Fig. 4 shows change of strains $\varepsilon_{t}$ and $\varepsilon_{z}$ with pressure, loaded up to $9 \mathrm{MPa}$ and $12.05 \mathrm{MPa}$. Circumferential strain was measured by strain gauge 27 , whereas axial strain was measured using strain gauge 23 .

Residual stresses that have occurred after the second test stage affected the way in which stress changed with strain in the third stage, in the sense of causing it to deviate from the previous proportionality, for pressures below $9 \mathrm{MPa}$. Further increase in pressure lead to increased strain rate, whereas the stress changed in non- 
linear manner. For the maximum pressure in the third stage, equivalent stress $\sigma_{i}$ was calculated, by using von Mises relation:

$$
\begin{aligned}
\sigma_{i} & =\sqrt{\sigma_{t}^{2}-\sigma_{t} \sigma_{z}+\sigma_{z}^{2}} \\
\sigma_{i} & =38.71 \cdot p
\end{aligned}
$$

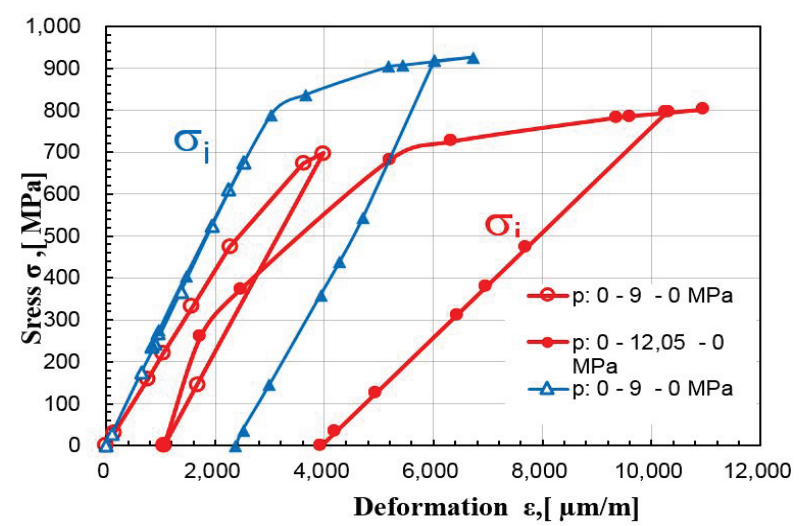

Figure 3 Stress strain diagram for the parent material

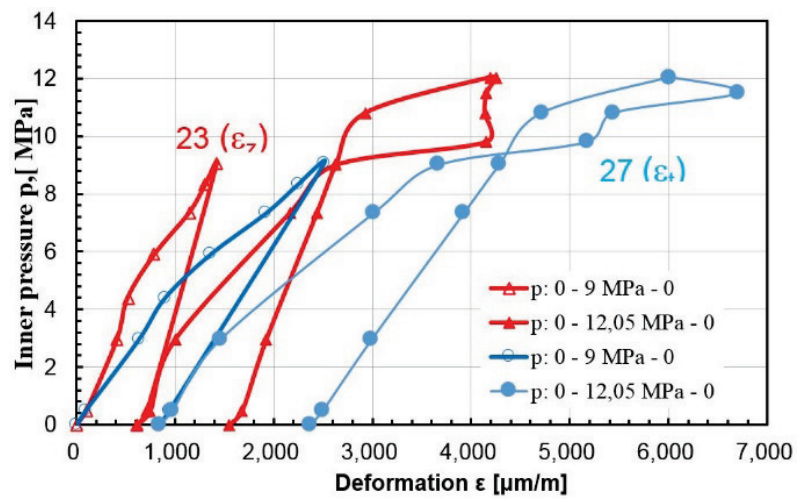

Figure 4 Strain change with pressure in welded joint LS4, for strain gauges 27 $\left(\varepsilon_{t}\right)$ and $23\left(\varepsilon_{z}\right)$

As one can see, Figs. 3 and 4, maximal residual (plastic) strain is $0.24 \%$ (strain gauges 27 ) in welded joint
LS4. Proportional behaviour during the second stage of testing can be observed, whereas unusual "loop" behaviour has been recorded in the third stage, as explained in [14].

\section{NUMERICAL SIMULATION OF LS4 WELDED JOINT BEHAVIOUR}

As already mentioned, numerical simulation based on the experimentally obtained results was also performed in order to obtain the stress/strain distribution. Aim was to compare numerical and experimental results and their verification [15-17]. This section of the paper includes the numerical analysis of welded joint LS4, subjected to a pressure of $12.05 \mathrm{MPa}$. The simulation is very similar to the previous work involving the plastic deformation of welded joint LS1, [18], and once again involves an undermatched weld, due to the use of submerged arc welding procedure. The goal here was to obtain equivalent strain which would be similar to the experimental values $[1,12]$.

In this case, mechanical properties were defined for the parent material (Yield Strength $760 \mathrm{MPa}$ ) and two weld metals, which had somewhat different Yield Strengths, 687 $\mathrm{MPa}$ for SAW and $725 \mathrm{MPa}$ for MAW. Other properties were defined as for the true stress - true strain curves, in a way explained in more details in [19].

Boundary conditions and the mesh are shown in Fig. 5a. The bottom ring surface was fixed, whereas the top ring was constrained in all directions except along the y axis. This was due to the fact that the lower ring was reinforced along its circumference on the prototype, whereas the upper one was not, and in the experiment, it was able to expand in the radial direction.

The mesh was defined with finer elements in the regions of interest, being the circumferential weld $\mathrm{CS}$, since the strain gauges that were used as a reference were located near it, Fig. 5b. The total number of elements was 147400, whereas the total number of nodes was 223110 . Standard linear hex elements (C3D8R) were used for this simulation.

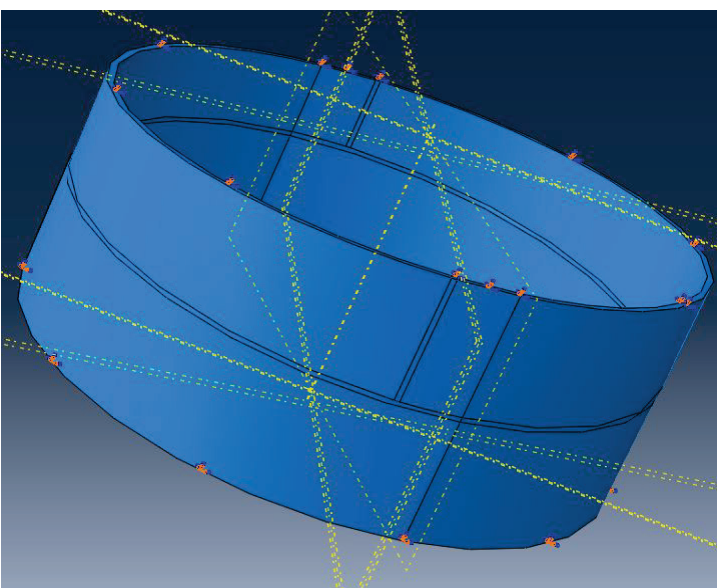

a)

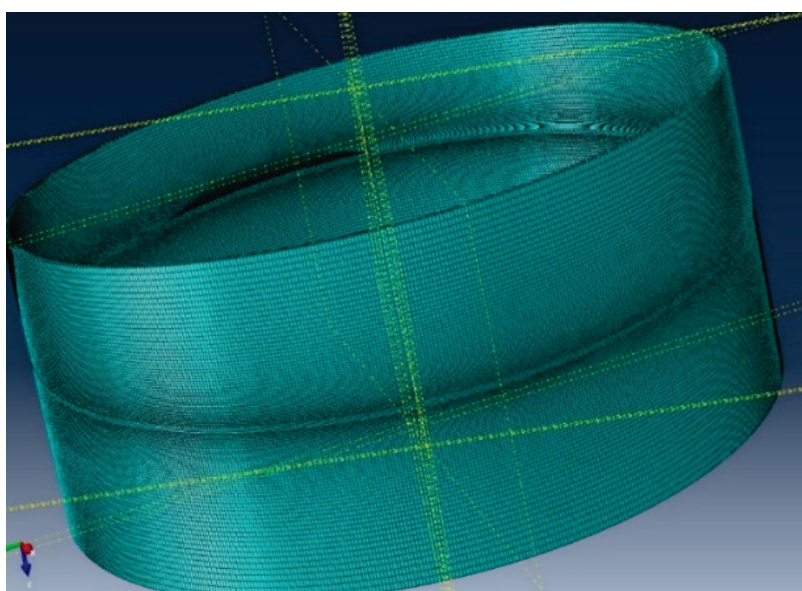

b)

Figure 5 Boundary conditions and the mesh of finite elements

Obtained results for equivalent strain distribution was compared with the experimental results for the same load, at the same locations (strain gauges 23 and 27 in the prototype).

Results of the numerical simulation are shown in Figs. $6 \mathrm{a}$ (stresses) and $6 \mathrm{~b}$ (strain). It can be seen that the stresses in the relevant location were around $763 \mathrm{MPa}$ (near the connection between the two welded joints), and were slightly above the Yield Strength for the weld metal (SAW), resulting in plastic strain, $0.25 \%$, which can be seen in Fig. $6 \mathrm{~b}$ as the total strain $(0.55 \%$, including cca $0.3 \%$ of elastic 
strain) and in Fig. 7. These values are in excellent agreement with experimental one, being $0.24 \%$ for the plastic strain, and $0.66 \%$ for the total value, Figs. 3 and 4 . Plastic strain concentration in the upper right corner can be disregarded since it was in the area where boundary conditions were defined.
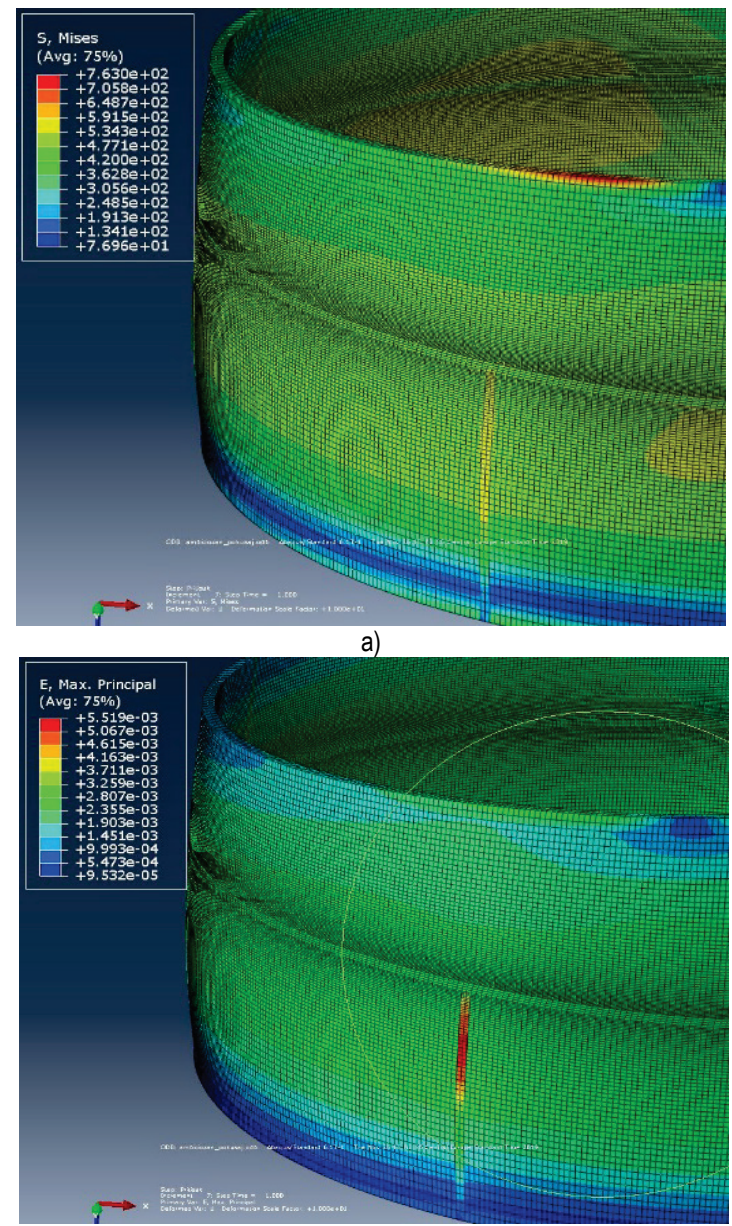

b)

Figure 6 Results of the numerical simulation: a) stresses; b) strains

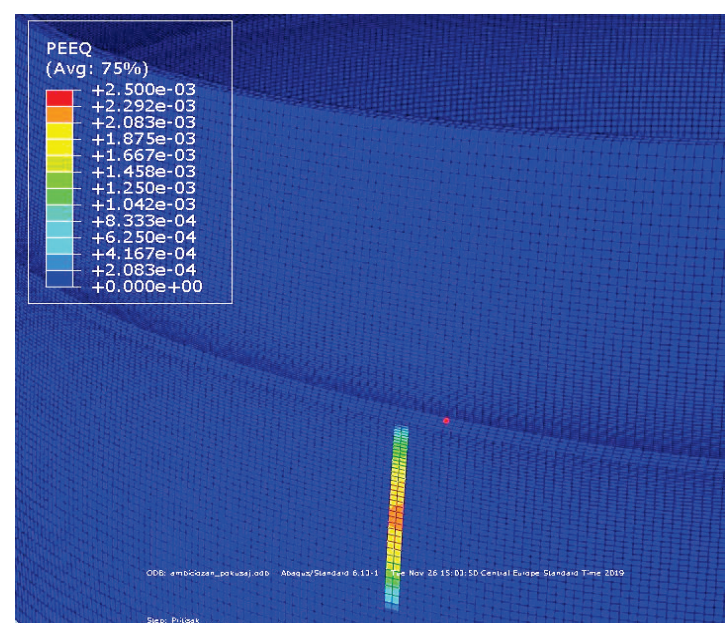

Figure 7 Equivalent plastic strain distribution

Following the simulations shown above, an additional case was also considered. In this case, it was assumed that the penstock was made of steel SM60 instead of the original parent material. It should be noted that this material was actually used as the parent material for the remaining parts of the HEPP "Bajina Bašta" pipeline.
Fig. 8 shows the equivalent plastic strain magnitudes and distribution, with the same test load of $12.05 \mathrm{MPa}$. As expected, there was an increase in maximum values, of around $10 \%$ compared to the results from Fig. 7 . In this case, however, plastic strain was present in a significantly larger number of places, and "covered" a much larger area. Since its maximum and other relevant values were distributed in a similar way to the SM80P case, it was decided to focus on the circumferential weld this time, since that one was not previously considered.

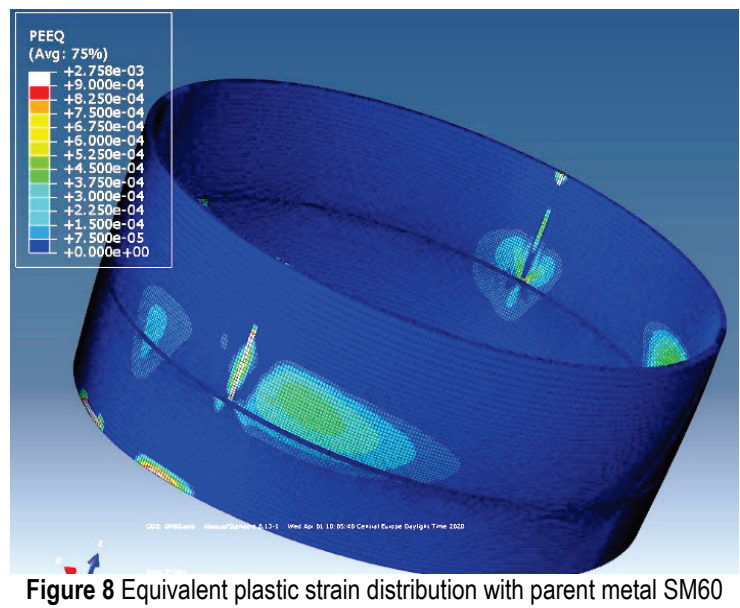

Fig. 9 shows the most critical region in the vicinity of the circumferential weld (CS), at its connection to the LS3 weld. Here the plastic strain was around $0.09 \%$, similar to the values obtained in the area where welded joints LS4 and CS meet, in the case of the previous model, with a stronger PM. The fact that this value was lower despite that suggests that the circumferential welded joint was not a critical location in neither of the cases, whereas the overall distribution of PEEQ in the second model numerically confirmed what was already known from experience - that a higher strength steel was necessary for this particular penstock.

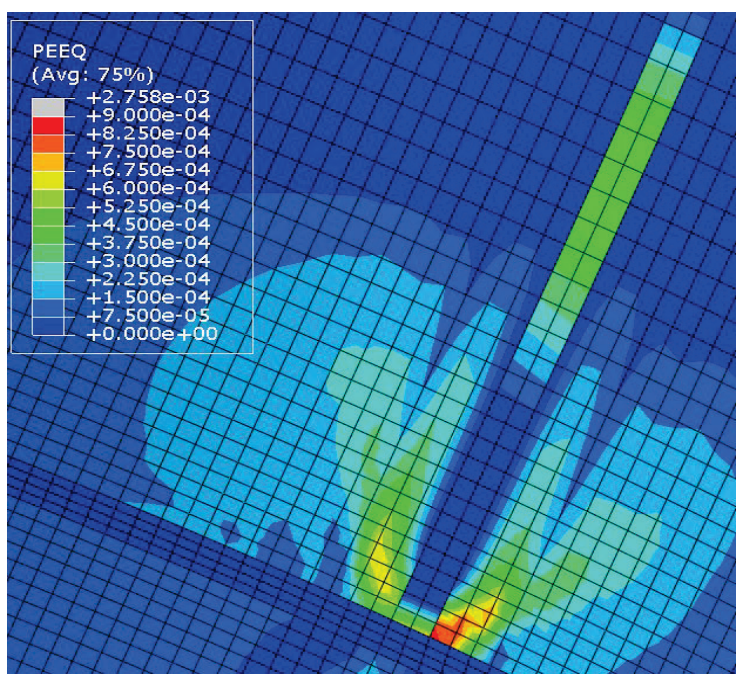

Figure 9 Equivalent plastic strain distribution with SM60 in the cirumferential weld

\section{DISCUSSION AND CONCLUSIONS}

Experimental tests of the prototype and its welded joints have shown that there are significant differences in terms of behaviour and properties of the parent material and the filler 
metals. The behaviour of a pressure vessel in exploitation is dictated by the welded joint.

Having in mind the fact that this experimental investigation confirmed that the unloaded vessel had shown completely elastic behaviour, it can be concluded that further increase in load will lead to plastic strain developing in regions where deformation was highest.

Numerical simulation of the prototype also showed similar behaviour as in the experimental conditions. This numerical model shows that the welded joints and base material have good performance at inner pressure of $12.05 \mathrm{MPa}$, which proves that the integrity of the penstock is not compromised. Additional models with the other material used in this pipeline had shown that the choice of SM80P was correct, as in this case there was noticeably more plastic strain involved.

Testing of weld metal and welded joint specimens supported the viewpoint that the weaker weld metal can be viewed as a "softer layer", providing additional plasticity to the penstock as a whole, and crucially contributing to its structural integrity. Anyhow, having in mind nowadays capabilities to manufacture overmatching welded joints which are not too sensitive to cracking, one should also consider this option when designing such a construction.

Based on presented results and their discussion, one can conclude that the integrity of the pipeline of HPP "Bajina Bašta" is not compromised, even when designed with a reduced degree of safety.

\section{Acknowledgments}

The authors of this paper would like to thank the Ministry of Education, Science and Technological Development of the Republic of Serbia for their support, subproject 34050 .

The authors wish to dedicate this paper to the memory of two great men and friends, Prof. Stojan Sedmak, Belgrade, and Prof. Zvonimir Lukačević, Slavonski Brod, who paved the way in this region of fracture mechanics and structural integrity of welded joints.

\section{REFERENCES}

[1] Sedmak, S. \& Sedmak, A. (1995). Experimental investigation into the operational safety of a welded penstock by a fracture mechanics approach. Fatigue and Fracture of Engineering Materials and Structures, 18, 527-538. https://doi.org/10.1111/j.1460-2695.1995.tb01415.x

[2] Gubeljak, N., Predan, J., Rak, I., \& Kozak, D. (2009). Integrity Assessment of HSLA Steel Welded Joint with Mis-Matched Strength. Structural Integrity and Life, 9, 157-164.

[3] Konjatić, P., Kozak, D., \& Gubeljak, N. (2012). The Influence of the Weld Width on Fracture Behaviour of the Heterogeneous Welded Joint. Key Engineering Materials, 488-489, 367-370. https://doi.org/10.4028/www.scientific.net/KEM.488-489.367

[4] Kozak, D., Konjatić, P., Matejiček, F., \& Damjanović, D. (2010). Weld Misalignment Influence on the Structural Integrity of Cylindrical Pressure Vessel. Structural Integrity and Life, 10(2), 153-159.

[5] Kozak, D., Gubeljak, N., Konjatić, P., \& Sertić, J. (2009). Yield load solutions of heterogeneous welded joints. International Journal of Pressure Vessels and Piping, 86, 807812. https://doi.org/10.1016/j.jpvp.2009.11.012

[6] Kozak, D., Gubeljak, N., \& Vojvodič Tuma, J. (2007). The effect of a material's heterogeneity on the stress and strain distribution in the vicinity of a crack front. Materials and technology, 41(1), 41-46.

[7] Gubeljak, N. (1999). Fracture behaviour of specimens with surface notch tip in the heat affected zone (HAZ) of strength mis-matched welded joints. International Journal of Fracture, 100(2), 155-167. https://doi.org/10.1023/A:1018794316336

[8] Bajić, D., Momčilović, N., Maneski, T., Balać, M., Kozak, D., \& Ćulafić, S. (2017). Numerical and experimental determination of stress concentration factor for a pipe branch model. Technical gazette, 24(3), 687-692. https://doi.org/10.17559/TV-20151126222916

[9] Younise, B. S. \& Sedmak, A. (2014). Micromechanical study of ductile fracture initiation and propagation on welded tensile specimen with a surface pre-crack in weld metal. Structural Integrity and Life, 14(3), 185-191.

[10] Bakić, G., Šijački-Žeravčić, V., Djukić, M., Rajičić, B., Radović, M., Gajić, I., Maslarević, A., \& Jakovljević, A. (2014). Characterisation of Undermatch Welded Joint of X20CrMoV121 Steel after Prolonged Service. Structural Integrity and Life, 14(2) (2014), 133-140.

[11] Schneider, C., Ernst, W., Schnitzer, R., Staufer, H., Vallant, R., \& Enzinger, N. (2018). Welding of S960MC with undermatching filler material. Welding in the World, March 62, 801-809. https://doi.org/10.1007/s40194-018-0570-1

[12] Sedmak, S. \& Sedmak, A. (2005). Integrity of Penstock of hydroelectric powerplant. Structural Integrity and Life, 5(2), 59-70.

[13] Čamagić, I., Burzić, Z., Sedmak, A., Vasić, N., Ćirković, B., $\&$ Algool, M. (2014). Influence of mechanical properties and microstructural heterogeneity of welded joint constituents on tensile properties and fracture toughness at plane strain, $\mathrm{K}_{\mathrm{Ic}}$. Structural Integrity and Life, 14(1), 45-49.

[14] Sedmak, S., Algool, M., Sedmak A., Tatic, U., \& Dzindo, E. (2016). Elastic-plastic behaviour of welded joints during loading and unloading of pressure vessels. $21^{\text {st }}$ European Conference on Fracture, Procedia Structural Integrity, 2, 3546-3553. https://doi.org/10.1016/j.prostr.2016.06.442

[15] Sedmak, S., Jovičić, R., Sedmak, A., Đorđević, B., \& Čamagić, I. (2017). Numerical analysis of different weld geometries of lap welded joint in ammonia transport tanks. Structural Integrity and Life, 17(3), 217-220.

[16] Martić, I., Sedmak, A., Mitrović, N., Sedmak, S., \& Vučetić, I. (2019). Effect of Over-Pressure on Pipeline Structural Integrity. Technical Gazette, 26(3), 852-855.

[17] Jovičić, R., Sedmak, S., Tatić, U., Lukić, U. \& Walid, M. (2015). Stress state around imperfections in welded joints. Structural Integrity and Life, 15(1), 27-29.

[18] Tatic, U., Sedmak, S., Djurdjevic, A., Sedmak, A., \& Bakić, R. (2013). Numerical modeling of full-scale penstock model testing. Proc. of the 3rd Int. Conf. Numerical Modeling of FullScale Penstock Model Testing, September 2013, Graz University of Technology - Austria. https://doi.org/10.1016/j.mspro.2014.06.183

[19] Sedmak, A. (2018). Computational fracture mechanics: An overview from early efforts to recent achievements. Fatigue \& Fracture of Engineering Materials \& Structures, 41(12), 2438-2474. https://doi.org/10.1111/ffe.12912

\section{Contact information:}

\section{Lazar JEREMIĆ, PhD student}

Innovation Centre of Faculty of Mechanical Engineering,

Kraljice Marije 16, 11120 Belgrade, Serbia

E-mail: laki991@hotmail.com

\section{Aleksandar SEDMAK, Prof. PhD}

(Corresponding author)

Faculty of Mechanical Engineering, University of Belgrade,

Kraljice Marije 16, 11120 Belgrade, Serbia

E-mail: asedmak@mas.bg.ac.rs 
Blagoj PETROVSKI, Prof. PhD

Innovation Centre of Faculty of Mechanical Engineering,

Kraljice Marije 16, 11120 Belgrade, Serbia

E-mail: bpetrovski@mas.bg.ac.rs

Branislav ĐORĐEVIĆ, PhD student

Innovation Centre of Faculty of Mechanical Engineering,

Kraljice Marije 16, 11120 Belgrade, Serbia

E-mail: brdjordjevic@mas.bg.ac.rs

Simon SEDMAK, PhD

Innovation Center of Faculty of Mechanical Engineering,

Kraljice Marije 16, 11120 Belgrade, Serbia

E-mail: simon.sedmak@yahoo.com 